\title{
SAMPLING METHODS IN LOG SCALING
}

\author{
BY I. F. FOGH
}

Canadian International Paper Co,, Three Rivers, Quebec

\begin{abstract}
Studies made by B. R. Lexen, Senior Silviculturist at the Rocky Mountain Forest and Range Experiment Station, Fort Collins, Colorado, U.S.A., on the application of sampling methods in the scaling of lodgepole and ponderosa pine logs are extended to the scaling of spruce and balsam bolts and small logs in Eastern Canadian pulpwood operations. It was found that Iexen's conclusions held good. Three general methods are available-(1) Random Sampling, (2) Representative or Stratified Random Sampling, and, (3) Mechanical Sampling. Th

A Random Sampling of two percent provides a reasonably close estimate of the total but refinements in technique and intensification in sampling are necessary if great accuracy is desired. Three refinements in technique are outlined.

Mechanical Sampling provides an unbiased estimate of the mean but evaluation of sampling error must be based on Random Samples. Due to ease of application in the field Mechanical Sampling is preferable.
\end{abstract}

$\mathrm{T}$

HE AIM of any sampling process is to obtain an estimate of certain characteristics of the population sampled and, at the same time, to assess the magnitude of the discrepancy between the true, but unknown, value of these characteristics and their estimates as derived from the sample. The evaluation of this discrepancy-or sampling error-serves to indicate the reliability of the estimate and it is evident that any sampling procedure must be so planned that this sampling error may be determined without bias and shall have the smallest value consistent with the budgetary considerations of the investigation.

The scaling of logs for the purpose of settling contractors' accounts can. not, for obvious reasons, be carried out as a sampling process. Log scaling has, however, numerous other purposes which do not involve the issues of a commercial transaction and for which a properly planned sampling procedure offers the combined advantages of a material reduction in scaling time and a degree of precision which is in exact accord with the subject of inquiry. As examples may be mentioned the scaling of logs in mill booms, or on jacklad. der, for the purpose of checking yard inventories or woods scales, and the scaling of bolts in a block pile for the purpose of determining displacement conversion factors.

A thorough investigation of the application of sampling to log scaling has recently been carried out by Mr. B. R. Lexen, Senior Silviculturist, Rocky Mountain Forest and Range Experiment Station, Fort Collins, Colorado ${ }^{1}$, demonstrating that acceptable estimates of board foot volume can be obtained by applying sampling technique to log scaling and that this technique can be so designed that any degree of precision may be obtained. The material investigated by $\mathrm{Mr}$. Lexen consisted of lodgepole pine and ponderosa pine, averaging respectively some $40 \mathrm{bd}$. ft. and $250 \mathrm{bd}$. ft. (Scribner rule) to the $\log$, and the question naturally arises as to the application of the conclusions drawn from tests on large timber in the West to small pulpwood species in the East.

1. Lexen, B. R. The application of sampling to log scaling. Journ. of For., Vol. 39:7. July, 1941. 
The present article outlines the results obtained by applying the theory of sampling to several sets of scale cards on which the volumes of 10,000 individual logs were entered. Logs were scaled in cubic feet according to the standard Province of Quebec procedure. Two species, spruce and balsam, were represented in the scales but were not differentiated in the analysis.

Several log lengths, from $4 \mathrm{ft}$. bolts to $16 \mathrm{ft}$. logs, were investigated sep. arately. The average log ranged from $.65 \mathrm{cu}$. ft. for $4 \mathrm{ft}$. bolts to $4.52 \mathrm{cu}$. ft. for $16 \mathrm{ft}$. logs.

An amazing similarity to the results obtained by Mr. Lexen with large logs in the West was the outstanding result of the investigation. Some minor differences were, however, noted and these may no doubt be ascribed to inherent characteristics of log aggregates consisting of very large and very small $\log s^{2}$.

The object of sample log scaling is to obtain an unbiased estimate of the volume of the average log which in turn, when combined with a log count, yields an estimate of the aggregate volume of all logs in the population. The efficiency of any method of sampling, as measured by the standard error of the mean,

$$
\text { Expression (1) } S_{m}=\frac{S}{\sqrt{n}}
$$

where $\mathrm{Sm}=$ standard error of the mean; $\mathrm{S}=$ the standard deviation; and, $\mathrm{n}=$ number of independent observations, is determined by the amount of variation, expressed by "S", within the population to be sampled and by the number of independent observations, " $\mathrm{n}$ ", constituting the sample. In planning a sampling procedure it is, therefore, desirable to obtain the smallest possible value of "Sm" consistent with the time and money available for the investigation. It is evident from Expression (1) that a reduction in the value of " $\mathrm{S}$ " or an increase in the value of " $\mathrm{n}$ ", or both together, will accomplish this result. There are three general methods of sampling available in log scaling. These are: Unrestricted Random Sampling, Representative or Stratified Random Sampling, and Mechanical Sampling. Each of these methods differs in efficiency and in the values of the estimates of "S" and "Sm" derived from the sample and will be discussed in turn.

\section{UNRESTRICTED RANDOM SAMPLING}

This method consists in the scaling of logs completely at random through the population to be sampled. Obviously, the greater the number of logs scaled, the smaller the value of the standard error (see Expression (1)). The

2. No originality is claimed for this investigation. The statistical analysis of sample log scaling applied to small logs was suggested by Mr. Lexen's article referred to in (1). The writer takes this opportunity to thank Mr. Lexen for his kind assist 
standard deviation is computed from

$$
\text { Expression (2) } S=\sqrt{\frac{S(x-\bar{x})^{2}}{n-1}}
$$

where $S=$ standard deviation; $S(x-\bar{x})^{2}=$ sum of squares of the deviations from the mean; and, $n-1=$ total number of observations less one, and it is evident that the value of "S" cannot be greatly affected by scaling a large number of logs. In fact, the standard deviation may be fairly closely estimated from a relatively small number of observations. Table I shows the results of four unrestricted random samples from spruce and balsam logs. Each sample consisted of 200 logs drawn at random from a population of 10,000 logs.

Table I. Statistics for Four 200-Log Samples hrom a Population of 10,000 Logs

\begin{tabular}{|c|c|c|c|c|c|c|c|}
\hline $\begin{array}{c}\text { Sample } \\
\text { No. }\end{array}$ & Mean & $\begin{array}{l}\text { Standard } \\
\text { deviation }\end{array}$ & Deviation & $\begin{array}{l}\text { from } \\
\text { Mean }\end{array}$ & Population & Standard Error of & Mean Log \\
\hline $\begin{array}{l}1 \\
2 \\
3 \\
4\end{array}$ & $\begin{array}{c}\text { cu. ft. } \\
4.48 \\
4.20 \\
4.22 \\
4.08\end{array}$ & $\begin{array}{c}\text { cu. ft. } \\
3.05 \\
3.00 \\
2.52 \\
2.76\end{array}$ & $\begin{array}{r}\text { cu. ft. } \\
+.20 \\
-.08 \\
-.06 \\
-.20\end{array}$ & & $\begin{array}{r}\text { Percent } \\
+4.67 \\
-1.87 \\
=1.40 \\
-4.67\end{array}$ & $\begin{array}{l}\text { cu. ft. } \\
.22 \\
.21 \\
.18 \\
.20\end{array}$ & $\begin{array}{c}\text { Percent } \\
5.14 \\
4.91 \\
4.21 \\
4.67\end{array}$ \\
\hline
\end{tabular}

True population average log: $4.28 \mathrm{cu} . \mathrm{ft}$.

True population stand. dev.: $2.94 \mathrm{cu}$. $\mathrm{ft}$.

It is apparent that even a 2 per cent randomly selected sample estimates the true average $\log$ of the $10,000 \log$ population with fair accuracy. The standard error of the mean $\log$ measures the reliability of the sampling, the average value for the four samples being 4.73 per cent of the true mean. Since, however, one in every three sample estimates may be expected to de. viate more than this amount and one in every twenty more than twice the amount, it is evident that the technique must be refined if greater precision in the result is desired.

The obvious way of increasing sample precision, when unrestricted random sampling is the method used, is to increase the number of independent observations, "n", in Expression (1).

What happens is easily determined by combining the four 2 per cent random samples from Table I into one 8 per cent random sample. The result. ing statistics are given in Table II.

Table II. Statistics for ONe 800-Log Sample from Population of 10,000 Logs

\begin{tabular}{|c|c|c|c|c|c|}
\hline Mean & $\begin{array}{l}\text { Standard } \\
\text { deviation }\end{array}$ & Deviation from & Population Mean & Standard Error & of Mean Log \\
\hline $\begin{array}{c}\text { cu. ft. } \\
4.25\end{array}$ & $\begin{array}{c}\text { cu. ft. } \\
2.83\end{array}$ & $\begin{array}{l}\text { cu. ft. } \\
-.03\end{array}$ & $\begin{array}{c}\text { Percent } \\
-.70\end{array}$ & $\begin{array}{c}\text { cu. ft. } \\
.10\end{array}$ & $\begin{array}{c}\text { Percent } \\
\mathbf{z . 3 4}\end{array}$ \\
\hline
\end{tabular}

It is seen that quadrupling the number of independent observations results in a 50 per cent reduction of the standard error and it is evident that the number of observations necessary to give any desired degree of precision may be determined by solving Expression (1) for " $n$ ", once the value of " $S$ " has been determined. Later, an easy method of determining " $n$ " will be given. 


\section{Representative or Stratified Random Sampling}

This method consists in subdividing the population into units or strata, generally of equal size, and drawing a representative set of samples, consisting of a ranclom sample containing at least two sampling units, from each stratum of the population. This process of subdivision ensures that all portions of the total population will be represented in the sample and is an improvement over the method previously discussed as it tends to lower the value of " $\mathrm{S}$ " (in Expression (1)), due to the fact that means of samples drawn by representative sampling methods tend towards a narrower dispersion around the true population mean than do the means of unrestricted random samples.

In representative or stratified random sampling the standard deviation is no longer determined from Expression (2), but the sum of squares, $S(x-\bar{x})^{2}$ is broken up into two parts, each traceable to a specified source. The first part is associated with the random variation between the strata and the second with the random variation within the strata. Together they add to the total sum of squares representing the random variation in the entire sample due to both sources. It is from the second part of the total sum of squares that the improved estimate of the standard deviation is obtained ${ }^{3}$. The Expression for this subdivision of the total sum of squares is

$$
=k S\left(\bar{x}_{p}-\bar{x}\right)^{2}+S S\left(x_{p}-\bar{x}_{p}\right)^{2}
$$

in which the left member is the sum of squares of deviations of all items from the general mean, " $\bar{x}$ ". The first term in the right member is the sum of squares between strata means, " $\bar{x}_{p}$ " , representing successively the " $n$ " such means and multiplied by the number of observations in a stratum. The last term is the sum of the " $n$ " sums of squares of deviations of stratum items from the stratum mean.

Table III shows the result of this allocation of total variation within a $\log$ population to the two sources associated with the strata and with the logs within the strata. A stratified sample composed of two logs selected at random from each of one hundred $100 \cdot \log$ strata in a total population of 10,000 logs was taken and the sums of squares broken up in its component parts as outlined above.

Table III. ANalysis of Variance for a 2 Per Cent Stratified Sample Taken from a total Population of 10,000 LOGS

\begin{tabular}{ll|c|c|c|c}
\hline Source of Variation & $\begin{array}{c}\text { Degrees } \\
\text { of freedom }\end{array}$ & $\begin{array}{c}\text { Sum of } \\
\text { Squares }\end{array}$ & $\begin{array}{c}\text { Mean } \\
\text { Square }\end{array}$ & $\begin{array}{c}\text { Standard } \\
\text { deviation }\end{array}$ \\
\hline Between strata & $\kappa S\left(\bar{x}_{p}-\bar{x}\right)^{2}$ & No. & $\begin{array}{c}\text { cu. ft. } \\
1201.48\end{array}$ & cu. ft. \\
12.14 & cu. ft. \\
Within strata & $S S\left(x_{p}-\bar{x}_{\beta}\right)^{2}$ & 99 & 936.27 & 9.36 & 3.06 \\
\hline Total & 100 & 199 & 2137.75 & 10.74 & \\
\hline
\end{tabular}

3. See any standard text on statistical analysis For Ex. Goulden C.H., Methods of Statistical Analysis, John Wiley and Sons, N.Y., 1939. 
The standard deviation is legitimately computed as the square root of the mean square for "within strata". The degrees of freedom represent the number of independent observations entering into the determination of each mean square. It is seen that, due to the breaking up of the "total" sum of squares into component parts, the mean square for "within strata" must be smaller than the mean square for the "total". An improvement in the reliability of the sample has thus been brought about by the stratification process as compared with an unrestricted random samplet.

The gain in efficiency brought about by stratification may, for the above sample, be expressed as

$$
\frac{(10.74-9.36) 100}{10.74}=
$$

assuming that the "total" mean square is equal to that for an unstratified sample. One may conclude from the above discussion that some form of stratification should always be resorted to in sample log scaling.

The effects on the estimated sampling error of sample size and strati. fication having been examined, there remains the question of the effect of sampling unit size in representative sampling ${ }^{5}$. For several reasons, such as a desire to save time or because of some structural peculiarity of the log aggregate to be sampled, it may seem advantageous to select sample logs in groups of five, ten or more. The effect of such grouping on the standard error of the mean is very marked. Table IV shows the results of taking 10 per cent samples of logs drawn singly and in groups of $5,10,20,50,100$ and 250 from the the same population of 10,000 logs.

Table IV. Statistics and Fffichency of Stratified Samples Composed of

\begin{tabular}{|c|c|c|c|c|c|}
\hline $\begin{array}{c}\text { Sample } \\
\text { No. }\end{array}$ & $\begin{array}{l}\text { No. of logs in } \\
\text { Sampling Unit }\end{array}$ & $\begin{array}{l}\text { No. of Units } \\
\text { in Sample }\end{array}$ & $\begin{array}{l}\text { Variance of } \\
\text { a single log }\end{array}$ & $\begin{array}{c}\text { Stand. Error of mean } \\
\text { log for sample }\end{array}$ & Efticiency \\
\hline $\begin{array}{l}1 \\
\mathbf{2} \\
\mathbf{3} \\
\mathbf{4} \\
\mathbf{5} \\
\mathbf{6} \\
7\end{array}$ & $\begin{array}{r}\text { No. } \\
1 \\
5 \\
10 \\
20 \\
50 \\
100 \\
250\end{array}$ & $\begin{array}{r}\text { No. } \\
1000 \\
200 \\
100 \\
50 \\
20 \\
10 \\
4\end{array}$ & $\begin{array}{r}\text { cu, ft. } \\
7.744 \\
11.649 \\
13.799 \\
16.641 \\
\mathbf{2 2 . 2 0 1} \\
30.896 \\
57.023\end{array}$ & $\begin{array}{r}\text { cu. ft. } \\
.088 \\
.108 \\
.117 \\
.129 \\
.149 \\
.175 \\
.239\end{array}$ & $\begin{array}{c}\text { Percent } \\
100 \\
66 \\
56 \\
47 \\
35 \\
25 \\
14\end{array}$ \\
\hline
\end{tabular}
SAMPLING UNITS OF DIFFERENT Sizes.

4. Tests of significance of the difference between the mean squares for "between" and "within" strata failed to show that this difference might be attributed to anything but chance variation in numerous stratified samples taken from populations of small logs. In this respect the results of this analysis differed from those obtained by Lexen in his studies of large logs in the West, where these differences tested highly significant. The conclusion is that populations of small logs are essentially homogeneous but that it, nevertheless, is advantstratification is present or not. In general, one can only enhance the efficiency by stratification.

5. The term sampling unit refers to a constituent part of the sample which is drawn independently and at random. It may consist of one or more ultimate units. In sample log scaling, the ultimate unit consists of a single log, while a sampling unit may consist of one or several logs forming a contiguous group. 
The ratio of the variance (or squared standard deviation) of the single log sample to the variance of single logs, when they are used to make up sampling units of various sizes, expresses the efficiency rating of each method of sampling.

It is evident that the increase in the standard error of the mean, as logs are scaled together in groups of increasing size, makes single log scaling the most accurate method, whenever a sample composed of a given number of logs is taken.

Since, however, the scaling of logs in groups often is advisable from either a time saving point of view or because of the make-up of the population to be sampled, one needs only to increase the sample size in order to compensate for the loss in accuracy brought about by scaling logs in groups. If, for example, conditions or the time factor indicate that logs should be scaled in groups of 100 , it is necessary to scale about four times as many logs in order to retain the accuracy desired. The chart in Fig. 1 will facilitate the determination of the efficiency ratings of sample log scales based on groups of different sizes". The drop in efficiency brought out in the above analysis may be rationalized on the grounds that any given number of log samples scattered uniformly and singly over a total population gives a better cross section of the various sizes present than do groups of large numbers of logs. Any group selected as a sample may be composed of mostly small or large logs and, in order to offset this, it would be necessary to take several more groups of the same size.

Representative sampling and sampling unit size can thus be effectively employed in reducing the standard deviation "S", and, consequently, in securing greater accuracy. A reduction in " $\mathrm{S}$ " may also be obtained by collecting additional information on some factor directly correlated with volume, such as diameter, but this method, involving indirect estimates through regression, is beyond the scope of this inquiry?

\section{MECHANICAL SAMPLING}

So far, the sampling methods discussed have been based exclusively on randomly drawn observations, either unrestricted or restricted through stratification. The reason for this is that we have been primarily concerned with the evaluation of sampling error and means for its reduction. The obvious and time honored method of selecting samples, in practice, has always been some form of mechanical selection, strips and plots in timber cruising, systematically selected logs or groups of logs at equal intervals in sampling for volume, etc., with the combined object of facilitating field work and eliminating personal bias. Unfortunately, however, such mech-

6. The rate of drop in efficiency by scaling logs in groups was found to be considerably less in the small logs analyzed by the writer. Lexen found a much more rapid falling off in the efficiency for large logs in the West, as the sampling unit size was increased. Evidently this effieiency drop is correlated with log size, although the figures found probably hold this effieincy drop is correlated with log si

7. See Schumacher, F. X., and Chapman, R. A., Sampling Methods in Forestry and Range Management, Duke University School of Forestry, Bulletin 7, 1942. 
LOG SCALING--FOGH

133

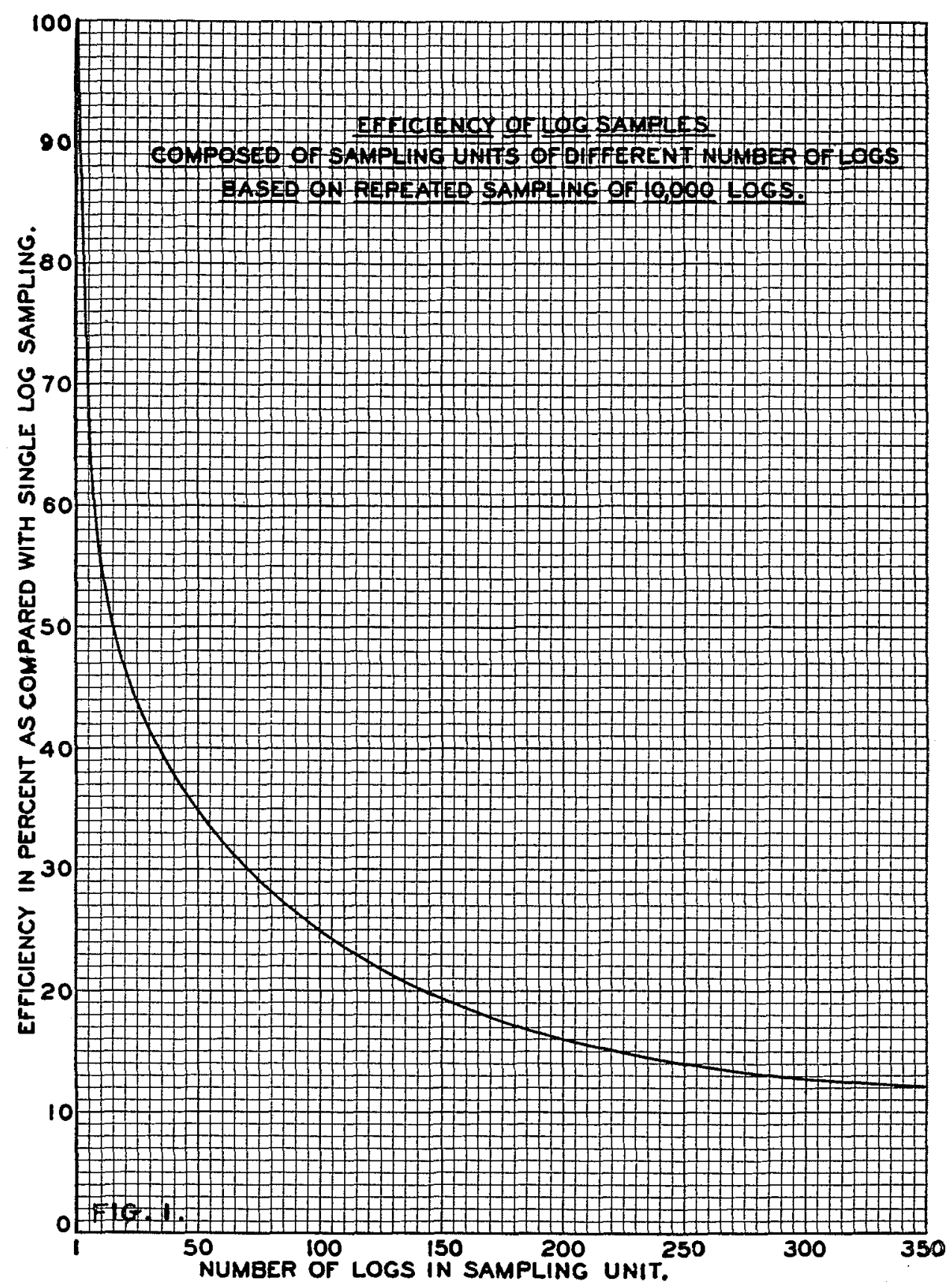


anical samples do not, in themselves, contain the information sufficient and necessary for the evaluation of sampling error, due to their failure to conform with the fundamental requirement of the solution of sampling prob. lems which implies that, during the sampling process, every item in a population shall have the same chance of being selected as any other item. The only way of accomplishing this is to locate each constituent part upon which sampling error is based independently and at random. Individuals in natural populations, such as log aggregates, are practically never arranged independently and at random-if they were, a mechanical sample would also be a random sample-but some form of stratification is always present. For this reason, mechanical samples are unsuited for the evaluation of sampling error ${ }^{8}$.

The drawing of random samples, in field work, is considerably less con. venient than mechanical selection but as, from an economic standpoint, it is important to predetermine the size of sample which is sufficient for an assumed maximum error, it is necessary, on the grounds outlined above, to take a preliminary sample of the population by random methods in order to obtain a valid estimate of sampling error upon which this determination of sample size may be based.

Once this information has been obtained, the selection of logs for sample log scaling may proceed by mechanical means, i.e., by scaling logs, or groups of logs, at regularly spaced intervals through the population, without introducing bias into the estimate of the mean. Table $\mathrm{V}$ shows the statistics for four 2 per cent random and four 2 per cent mechanical samples drawn from the same population of 10,000 logs.

Table V. Statistics for Four 2 Per Cent Random and Four 2 Per Cent MEChanical SAMples of 10,000 Logs

\begin{tabular}{|c|c|c|c|c|c|c|c|c|c|c|}
\hline \multicolumn{6}{|c|}{ Random Samples } & \multicolumn{5}{|c|}{ Mechanical Samples } \\
\hline $\begin{array}{c}\text { Sample } \\
\text { No. }\end{array}$ & Mean & $\begin{array}{l}\text { Standard } \\
\text { Deviation }\end{array}$ & $\mid \begin{array}{c}\text { Standard } \\
\text { Error }\end{array}$ & \multicolumn{2}{|c|}{ Deviation } & Mean & \begin{tabular}{|c|} 
Standard \\
Deviation
\end{tabular} & $\begin{array}{c}\text { Standard } \\
\text { Error }\end{array}$ & \multicolumn{2}{|c|}{ Deviation } \\
\hline $\begin{array}{l}1 \\
2 \\
3 \\
4\end{array}$ & $\begin{array}{r}\text { cu. ft. } \\
4.09 \\
4.25 \\
4.55 \\
4.25\end{array}$ & $\begin{array}{c}\text { cu. ft. } \\
2.52 \\
2.72 \\
3.02 \\
2.38\end{array}$ & $\begin{array}{r}\text { cu. } f t . \\
.18 \\
.19 \\
.21 \\
.17\end{array}$ & $\begin{array}{l}\text { cu. ft. } \\
-.19 \\
. .03 \\
+.27 \\
-.03\end{array}$ & $\begin{array}{c}\text { Per cent } \\
-4.44 \\
-.70 \\
+6.30 \\
-.70\end{array}$ & $\begin{array}{r}\text { cu. } \mathrm{ft} \\
4.20 \\
4.61 \\
4.38 \\
4.49\end{array}$ & $\begin{array}{r}\text { cu. ft. } \\
2.87 \\
2.96 \\
3.60 \\
3.48\end{array}$ & $\begin{array}{c}\text { cu. ft. } \\
.20 \\
.21 \\
.25 \\
.25\end{array}$ & $\begin{array}{c}\text { cu. ft. } \\
+.08 \\
+.23 \\
+.10 \\
+.21\end{array}$ & $\begin{array}{r}\% \\
-1.87 \\
+5.37 \\
+2.33 \\
+4.31\end{array}$ \\
\hline Average & 4.29 & 2.67 & & +.01 & +.23 & 4.40 & 3.24 & & +.12 & +2.80 \\
\hline
\end{tabular}

True average log: $4.28 \mathrm{cu}$. $\mathrm{ft}$.

The average for the mechanical samples shows a deviation of $.12 \mathrm{cu} . \mathrm{ft}$. from the true mean and the average of the random samples a deviation of $.01 \mathrm{cu} . \mathrm{ft}$. The deviations are thus in favor of random sampling but the differences are not great enough to be attributed to any other cause than chance variation. The standard errors calculated from the mechanical

8. Schumacher and Chapman, Op. Cit. 
samples are higher than those from the random samples indicating an upward bias in sampling errors as derived from observations which do not have an equal and independent chance of selection. In general, however, there is no reason to suspect that mechanical samples are not entirely adequate for obtaining an' unbiased estimate of the average log in sample log scaling.

\section{Determination of Sample Size}

As mentioned in the previous section it is necessary, when information pertaining to sampling error is lacking, to take a preliminary sample from the population, by random methods, in order to obtain the necessary information for the predetermination of sample size sufficient for an as sumed maximum error. As this is time consuming, as well as being somewhat involved for the ordinary scaler and as investigations of large logs in the West have shown a remarkable stability of the standard deviation in different log aggregates ${ }^{0}$, an analysis of small logs, in various length classes, was carried out, in order to determine whether or not this stability also was present in such material and to what extent it compared with large logs. Table VI shows the population means, standard deviations and coefficients of variation ${ }^{10}$ for several log aggregates composed of small logs in various length classes.

Table VI. Means, Standard Deviations and ComfFrctents of Vartation For SMall Logs of Various Length Classes

\begin{tabular}{|c|c|c|c|c|c|}
\hline Test & $\begin{array}{c}\text { Log } \\
\text { Length }\end{array}$ & $\begin{array}{l}\text { No. of } \\
\text { rogs }\end{array}$ & $\begin{array}{c}\text { Population } \\
\text { Mean }\end{array}$ & $\begin{array}{l}\text { Standard } \\
\text { Deviation }\end{array}$ & $\begin{array}{l}\text { Coefficient } \\
\text { of Varlation }\end{array}$ \\
\hline $\begin{array}{c}\text { No. } \\
1 \\
2 \\
3 \\
4 \\
5 \\
6\end{array}$ & $\begin{array}{r}\text { Ft. } \\
4 \\
4 \\
12 \\
14 \\
14 \\
16\end{array}$ & $\begin{array}{r}\text { No. } \\
578 \\
6,810 \\
29,229 \\
10,000 \\
58,164 \\
16,367\end{array}$ & $\begin{array}{r}\text { cu. ft. } \\
.66 \\
.67 \\
3.14 \\
4.28 \\
3.69 \\
4.62\end{array}$ & $\begin{array}{r}\text { cu. ft. } \\
.52 \\
.48 \\
2.55 \\
2.94 \\
2.84 \\
3.38\end{array}$ & $\begin{array}{c}\text { Per cent } \\
79.5 \\
70.9 \\
81.3 \\
68.7 \\
77.0 \\
94.8\end{array}$ \\
\hline
\end{tabular}

The stability of the coefficient of variation, irrespective of average log or log length, is marked and ranges from 69 to 81 per cent. The average is about 75 per cent and is almost identical with that found by Lexen in the West ${ }^{21}$. The conclusion is that, for practical purposes, the standard deviation of volume in log aggregates may be taken as 75 per cent of the mean, whether the logs are long or short, large or small, and this materially facilitates the determination of sample size sufficient for any assumed maximum error. The chart in Fig. 2, which is read in the manner of the conventional alignment chart by stretching a thread or ruler between the values of two variables on their graduated axes and reading the corresponding value of a third variable on its graduated axis, indicates the approximate number of logs, expressed in per cent of total number of logs, which

9. Lexen, Op. Cit.

expressed in per cent of the mean.

11. Lexen, Op. Cit. 
must be scaled in order to insure any chosen standard of accuracy ${ }^{12}$. For example, if 100,000 logs are to be sampled and the maximum acceptable error is 2 per cent, a straight line joining these values on the extreme left and right axes of the chart intersects the middle axis at 9 per cent on the right scale of the axis and 5 per cent on the left scale. Since these two scales are on the basis of probabilities 0.01 and 0.05 respectively, one may be certain that the estimate of the average log will contain an error larger than 2 per cent in only 1 sample out of 100 if 9 per cent, or every eleventh $\log$, is scaled, and in only 1 sample out of 20 if 5 per cent, or every twentieth $\log$, is scaled. There is reasonable certainty, therefore, that the estimate will deviate considerably less than 2 per cent from the true volume in the majority of cases. Just which scale on the middle axis one chooses depends entirely on the degree of confidence to be placed on the result. For most ordinary purposes the values given on the left scale should be adequate, as the odds are 19 to 1 against the error exceeding the chosen maximum error.

The chart may also be read in reverse. For example, if 50,000 logs have been sampled by scaling every fiftieth $\log$, or 2 per cent of the total, a line joining these values on the left and middle axes of the chart intersects the right axis at 4.6 per cent and 6.1 per cent respectively as the left or right scale on the middle axis is chosen. This indicates that the deviation of the estimate from the true volume can be expected to be less than plus or minus 4.6 per cent in 19 cases out of 20 , and less than 6.1 per cent in 99 cases out of 100 .

In using the chart, one should keep in mind the decrease in efficiency brought about by increasing sampling unit size and, if logs are to be scaled in groups, the proper correction should be made by reference to Fig. 1. Also, if there is reason to believe that variability in log volume is unusually great (or small as the case may be), a check should be made by taking a preliminary stratified random sample, and the sample size determined by solving Expression (1) for " $n$ "13.

12. A similar chart has been given by Lexen in his article (1). Fig. 2 differs from the chart prepared by Lexen in certain minor details only; notably, in that it makes allowance for amall correction factor for limited populations; in that the required sample size for given maximum error is expressed on the basis of two different probability levels; and, in that no added amount as a safety factor has been included in the coefficient of variation (75 per cent) which has been used as a basis for the chart. The latter has been omitted, as the odds against the mean of any one sample differing from the true mean by more than the indicated maximum error purposely have been chosen high.

13. The formula for standard error appropriate for means drawn from a limited population is

$$
S_{m}=\frac{S}{\sqrt{n}} \sqrt{1-\frac{n}{N}}
$$

where $\mathbf{N}=$ the total number of logs in the population.

This correction to Expression (1) is unnecessary for practical purposes, as long as " $n$ " compared with " $\mathrm{N}$ " is very small. 


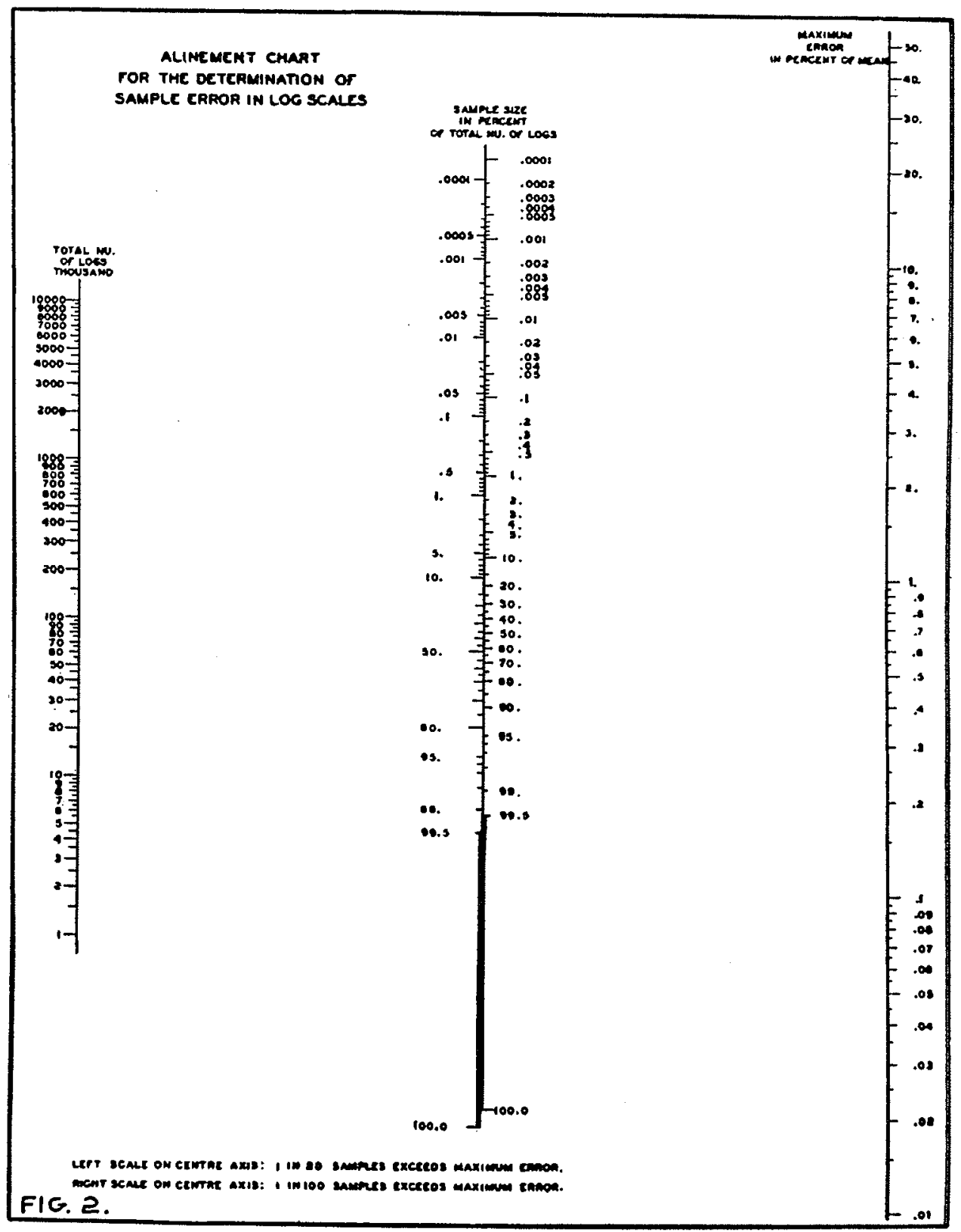




\section{SUMMARY}

From an extension of Lexen's study of the application of sampling technique to scaling of ponderosa and lodgepole pine logs in the West, it was found that his conclusions hold good also for small pulpwood species in the East.

A random sample of 2 per cent provides a reasonably close estimate of the total but, if great accuracy is desired, refinements in technique and intensification in the sampling are necessary.

These refinements in technique may take the form of:

1. An increase in the number of independent observations;

2. Stratification of the population to obtain a more representative sample;

3. A decrease in the sampling unit size to the minimum compatible with the time factor and physical structure of the log aggre. gate to be sampled. (Single log samples are most efficient).

Mechanical samples provide an unbiased estimate of the mean but evaluation of sampling error must be based on random samples. Due to the ease with which mechanical sampling is applied in the field, this method should be used.

No appreciable difference was found in the coefficient of variation for large or small, long or short logs. For practical purposes, the determination of sample size necessary for any chosen degree of accuracy may, therefore, be accomplished by reference to an "error chart" based on an average value of the coefficient of variation.

Proper allowance should be made for logs scaled in groups and, in cases of suspected high or low variability, a check should be taken preliminary to the decision as to sample size. 